\title{
El nuevo Código Procesal Constitucional peruano
}

Francisco Eguiguren Praeli"

La reciente aprobación del Código Procesal Constitucional peruano, mediante la ley 28237 publicada el 31 de mayo del 2004, cuya vigencia se iniciará luego de seis meses, resulta un hecho de particular trascendencia nacional y continental. Por un lado, porque se trata del primer código de un país latinoamericano que aborda, de manera orgánica, integral y sistemática, el conjunto de los procesos constitucionales y los principios procésales que los sustentan; por otro, porque la norma recoge importantes avances e innovaciones, provenientes de los aportes de la doctrina y jurisprudencia de la materia, a la par de corregir vacíos y deficiencias observadas en el funcionamiento y tratamiento judicial de la legislación precedente. Debe recordarse que la norma pionera fundamental en este campo, la ley 23506 de Hábeas Corpus y Amparo, data de fines de 1982, ha sufrido modificaciones parciales que, en la mayoría de casos, se dictaron para restringir sus alcances y eficacia.

La forma de elaboración y aprobación de este Código Procesal Constitucional ha sido también peculiar y novedosa, pues el anteproyecto no surgió de una comisión oficial, creada o convocada por los poderes Legislativo o Ejecutivo, sino de la iniciativa espontánea de un grupo de profesores de la Facultad de Derecho de la Pontificia Universidad Católica del Perú, vinculados a esta materia en lo académico y profesional. En efecto, a lo largo de ocho años Domingo García Belaunde, Juan Monroy Gálvez, Arsenio Oré Guardia, Jorge Danós Ordóńez, Samuel Abad Yupanqui y Francisco

* Jefe del Departamento Académico de Derecho de la Pontificia Universidad Católica del Perú. Profesor de Derecho Constitucional. Ex Director Ejecutivo de la Comisión Andina de Juristas, ex Director General de la Academia de la Magistratura del Perú. Juez ad hoc de la Corte Interamericana de Derechos Humanos. 
Eguiguren Praeli, se reunieron periódicamente para preparar el texto de un anteproyecto, que fue varias veces objeto de revisión y mejoramiento.

La realidad política y jurídica vivida en nuestro país durante el régimen fujimorista obligó a suspender varias veces la elaboración y discusión del anteproyecto, a la espera de contar con un escenario democrático que permitiera y justificara la presentación de esta propuesta a las autoridades legislativas y gubernamentales. Recién en octubre del 2003, la última versión del anteproyecto fue publicada en un libro y difundida por los autores, y se presentó oficialmente ante el Congreso, donde se convirtió en un proyecto legislativo multipartidario que se aprobó rápidamente con mínimas modificaciones a la versión original.

Debe precisarse que la propuesta del Código, con la intención de facilitar su aprobación y entrada en vigencia, se elaboró dentro de los marcos y límites fijados por las actuales normas constitucionales referidas al control de constitucionalidad y las "garantías constitucionales". Ello ha determinado que, en algunos casos (que afortunadamente no son muchos) no se haya podido introducir todos los cambios deseados por los autores del anteproyecto, en temas tales como la ampliación de la competencia del Tribunal Constitucional (TC) en materia de procesos constitucionales destinados a la protección de derechos, que sigue limitada a los casos con sentencia desestimatoria del Poder Judicial; o la eliminación de procesos constitucionales como la acción de cumplimiento o el hábeas data (que, propiamente, es un amparo especializado).

En cuanto a su estructura, el Código cuenta con un Título Preliminar y trece títulos, compuesto por 121 artículos, siete disposiciones finales y dos transitorias. En el Título Preliminar se fijan algunos principios y criterios generales, y existe un título que reúne disposiciones generales comunes para los procesos de hábeas corpus, amparo, hábeas data y cumplimiento; y otro título para las disposiciones generales comunes a los procesos de inconstitucionalidad y acción popular. Sin perjuicio de ello, existen también títulos específicos para la regulación detallada de cada uno de estos procesos, así como para el proceso competencial. Cabe destacar que el Código deja de lado la tradicional denominación de "garantías constitucionales", reemplazándola por la más moderna y técnica de "procesos constitucionales".

\section{El título preliminar del Código}

El Código cuenta con un Título Preliminar compuesto de nueve artículos. En el artículo II se señalan como fines de los procesos constitucionales "ga- 
rantizar la primacía de la Constitución y la vigencia efectiva de los derechos constitucionales». En el artículo III se establecen como principios procesales la dirección judicial del proceso, el impulso de oficio, la gratuidad, la economía, la inmediación y socialización procesales. Se impone al juez y al Tribunal Constitucional la obligación de impulsar de oficio los procesos, salvo en los casos expresamente excluidos por el Código, así como adecuar las formalidades al logro de los fines perseguidos por los procesos constitucionales. Añade el Código que, cuando en un proceso constitucional se presente una duda razonable respecto de si el proceso debe declararse concluido, el juzgador declarará su continuación. La gratuidad que rige para estos procesos no obstará para que la sentencia judicial definitiva pueda imponer como condena el pago de costas y costos.

El artículo V del Título Preliminar dispone que el contenido y los alcances de los derechos constitucionales deberán interpretarse de conformidad con lo estipulado en los tratados internacionales sobre derechos humanos de los que el Perú es parte y por las sentencias de los órganos de la jurisdicción internacional de la materia. Si bien esta norma recoge lo estipulado en la Cuarta de las Disposiciones Finales y Transitorias de la Constitución ${ }^{1}$ de 1993, agrega la referencia concreta a las decisiones de los tribunales internacionales de derechos humanos, y hace explícito el carácter vinculante de estas para la jurisdicción interna. Esta atingencia es muy importante, dado el aporte que en los últimos años viene haciendo la Corte Interamericana de Derechos Humanos en la aplicación e interpretación de diversos derechos consignados en el Pacto de San José, contribución acogida en numerosas sentencias de nuestro Tribunal Constitucional.

Pero debe también recordarse que esta Disposición de la Constitución tuvo una inclusión casi subrepticia y desapercibida en dicha Carta, pues los constituyentes fujimoristas suprimieron de manera expresa la referencia que hacía la Constitución de 1979 al rango constitucional de las normas sobre derechos humanos contenidas en tratados internacionales. Ello con la intención (después explicitada) de desvincularse del cumplimiento de estas normas y de la competencia de la Corte Interamericana de Derechos $\mathrm{Hu}$ manos. De allí que la existencia de la Cuarta Disposición Final y Transitoria de la Carta de 1993, ahora también recogida y desarrollada en el artículo V del Título Preliminar de este Código, permite afirmar, conforme lo ha asumido el TC en diversas sentencias, que al interpretarse los derechos constitucionales de conformidad con los tratados sobre derechos

Cuarta Disposición Final y Transitoria de la Constitución: "Las normas relativas a los derechos y libertades que la Constitución reconoce se interpretan de conformidad con la Declaración Universal de Derechos Humanos y con los tratados y acuerdos internacionales sobre las mismas materias ratificados por el Perú». 
humanos, estos tienen rango constitucional. Incluso, se podría decir que hasta rango supraconstitucional, pues si las normas de los pactos internacionales sobre derechos humanos ratificados por el Perú, y las sentencias de los órganos jurisdiccionales creados por estos, sirven como marco o parámetro para determinar la interpretación del contenido y alcances de los derechos constitucionales, aquellos preceptos internacionales no solo tendrían un rango similar sino superior a las normas constitucionales de la materia.

El artículo VI del Título Preliminar del Código se ocupa del control de la supremacia de la Constitución y de los efectos del denominado control difuso o incidental de inconstitucionalidad. Este control difuso tiene como sustento los artículos 51 y 138, segundo párrafo, de la Constitución perua$\mathrm{na},{ }^{2}$ que obligan a todo juez o magistrado, en cualquier tipo de proceso judicial, a preferir la norma constitucional sobre disposiciones legales o de inferior jerarquía en caso de existir conflicto entre estas, ordenando la inaplicación (para el caso concreto) de la norma considerada inconstitucional. El Código precisa que esta prevalencia en la aplicación del precepto constitucional se hará siempre que ello sea relevante para la decisión del caso y que no haya forma de interpretar la norma cuestionada de conformidad con la Constitución.

El artículo VI establece también que los jueces no podrán inaplicar (mediante el control difuso) una norma cuya constitucionalidad haya sido confirmada por el Tribunal Constitucional, en un proceso de inconstitucionalidad, o por el Poder Judicial, en un proceso de acción popular. Sin duda que estamos ante un claro límite a la aplicación del control difuso en sede judicial, que encontramos justificado no solo porque apunta a afianzar el papel rector que debe corresponder al TC en este campo, sino porque trata de dar coherencia y unidad de criterio a la decisión sobre la vigencia de las normas dentro del ordenamiento jurídico. Ello se complementa con el señalamiento por esta norma del Código respecto a que los jueces interpretarán las leyes y normas legales conforme a la interpretación que hagan de ellas las sentencias dictadas por el TC. Conviene tener presente que ni la Constitución ni la ley orgánica del Tribunal asignan expresamente a este órgano el carácter de supremo intérprete de la Constitución, refiriéndose a él como «órgano de control de la Constitución». No obstante, el TC, en muchas de sus sentencias sobre inconstitucionalidad, ha establecido que asume este rol de último y supremo intérprete de la Constitución, criterio que

Constitución, artículo 51: "La Constitución prevalece sobre toda norma legal; la ley, sobre las normas de inferior jerarquía, y así sucesivamente [...|».

Artículo 138, segundo párrafo: «En todo proceso, de existir incompatibilidad entre una norma constitucional y una norma legal, los jueces prefieren la primera. Igualmente prefieren la norma legal sobre toda otra norma de rango inferior". 
compartimos y que se ve fortalecido con la norma del Código que comentamos.

En el pasado, se dieron múltiples casos en los que los jueces y tribunales ordinarios, en sentencias que quedaron firmes, resolvieron inaplicar normas cuya constitucionalidad había sido previamente confirmada por el TC, y crearon incertidumbre jurídica sobre la validez y vigencia de tales normas. Puesto que en el Perú no se contempla la «cuestión de inconstitucionalidad" del sistema español, que remite necesariamente al TC la apreciación y decisión definitiva sobre la eventual inconstitucionalidad de una norma suscitada incidentalmente en cualquier proceso judicial, la limitación de los alcances del control difuso judicial -cuando el $\mathrm{TC}$ ya se ha pronunciado desestimando la inconstitucionalidad de una norma- aporta un mínimo de certeza y orden al sistema jurídico. También cabe considerar que existen casos de sentencias judiciales definitivas (de segunda instancia) en procesos de amparo que inaplican una ley por calificarla de inconstitucional, sin que esta decisión pueda llegar a revisión al TC, dado que la Constitución restringe su competencia en esta materia a los procesos con sentencia judicial denegatoria de la acción.

Por todo ello, esta disposición del Código contribuye a la mayor coherencia en cuanto a la aplicación de las normas del ordenamiento jurídico, a la par que atempera la inconveniente "dualidad" y falta de articulación que aún subsiste en el control de constitucionalidad, a cargo del Poder Judicial y el TC, en el "modelo" peruano. No debe olvidarse que la declaración de inconstitucionalidad de una ley o norma, en cualquier tipo de proceso, debe ser siempre asumida como una medida "última" o extrema, luego de haber intentado, sin éxito, encontrar alguna interpretación aceptable y razonable del precepto analizado, que lo haga conforme y compatible con la Constitución, pauta de interpretación que recoge esta norma del Código.

$\mathrm{El}$ artículo VII establece que las sentencias del TC que adquieran la autoridad de cosa juzgada, constituirán precedente vinculante cuando el Tribunal así lo disponga, y puede el propio TC apartarse de dicho procedente expresando los fundamentos de hecho y de derecho que sustentan y justifican esta decisión. Con ello, se aporta a la coherencia y previsibilidad de las decisiones judiciales en materia constitucional, superando una marcada deficiencia apreciada en los últimos años que impidió el establecimiento de una verdadera jurisprudencia. A su vez, se deja a criterio del TC determinar cuáles de sus sentencias o qué parte de estas fijan un precedente vinculante, evitando el otorgamiento mecánico de este carácter a todas sus decisiones. 


\section{La protección de los derechos constitucionales: los procesos de hábeas corpus, amparo y hábeas data}

La Constitución Peruana de 1993 se ocupa en su Tírulo V de las "Garantías Constitucionales". El artículo 200 de la Carta Política, en sus numerales 1,2 y 3 , establece los alcances básicos de los procesos de hábeas corpus, amparo y hábeas data, respectivamente; todos ellos son procedentes frente al hecho $\mathrm{u}$ omisión de cualquier autoridad, funcionario o persona que amenaza o vulnera determinados derechos constitucionales específicos. Nótese que estas acciones proceden, preventivamente, contra amenazas al derecho (que deben ser ciertas e inminentes) o ante la violación concreta, y pueden interponerse contra autoridades estatales o frente a particulares.

La diferencia sustancial entre estos tres procesos constitucionales está referida a los derechos específicos que cada uno protege. Así, el hábeas corpus tutela la libertad individual y los derechos constitucionales conexos con ella, tales como las vulneraciones a la seguridad e integridad personal, detención arbitraria, incomunicación, privación de defensa legal al detenido, hostigamiento policial, etcétera. El hábeas data protege dos derechos: a solicitar y obtener información que posean las entidades públicas, con el solo pago del costo que suponga el pedido, salvo en materias referidas a la intimidad personal, seguridad nacional o excluidas por ley; y la protección de los datos personales sensibles, referidos a la intimidad personal y familiar, respecto a su uso o suministro por parte de los «servicios informáticos» (registros, bancos de datos o archivos) sea que correspondan a entidades públicas o privadas. Por su parte, el amparo protege todos los demás derechos constitucionales no cautelados por el hábeas corpus y hábeas data; precisa la norma su improcedencia (directa) contra las normas legales o frente a resoluciones judiciales emanadas de un «procedimiento regular». Finalmente, la acción de cumplimiento, prevista en el numeral 6 del artículo 200 de la Constitución, procede contra cualquier autoridad o funcionario renuente a acatar lo dispuesto por una norma legal o acto administrativo.

El Código, en su Título I, contiene las disposiciones generales comunes a estos procesos, que se complementan con el tratamiento particular de cada uno de estos en otros títulos específicos de la ley. En cuanto al hábeas corpus, amparo y hábeas data, el artículo 1 del Código dispone que su finalidad es retrotraer las cosas al estado anterior a la amenaza o violación de un derecho constitucional.

Una innovación muy importante del Código, prevista en el segundo párrafo de su artículo 1, consiste en señalar que si la amenaza o violación del derecho cesa, luego de presentada la demanda, por decisión voluntaria del 
agresor o deviene en irreparable, la sentencia declarará fundada la acción y precisará los alcances de la resolución, y requerirá al emplazado para que no reitere la conducta dañosa bajo apercibimiento de imponerle medidas coercitivas. Ello constituye un claro avance respecto de la anterior ley, que disponía que si la vulneración del derecho cesaba o se convertía en irreparable, sin importar que ello sucediera después de interpuesta la demanda, la acción sería declarada necesariamente improcedente.

En el artículo 3 se regula la procedencia de estos procesos cuando la acción se dirige contra un acto que se ejecuta en aplicación de una norma legal incompatible con la Constitución. Nótese que no se trata de una acción directa contra la ley (solo factible mediante una acción de inconstitucionalidad) sino contra actos concretos que se realizan en cumplimiento de esta, por lo que, de declararse fundada la demanda, la sentencia dispondrá, además de la protección y restablecimiento del derecho, la inaplicación de la norma legal, considerada inconstitucional, para el caso concreto.

El artículo 4 del Código habilita la procedencia del hábeas corpus y amparo cuando la vulneración del derecho proviene de una resolución judicial firme, dictada con manifiesto agravio de la libertad individual o de la tutela procesal efectiva, respectivamente. Esta tutela procesal efectiva comprende el acceso a la justicia y el debido proceso, y tiene como componentes específicos: el libre acceso ante el órgano jurisdiccional, el derecho a probar, a la defensa y al contradictorio, a la igualdad sustancial dentro del proceso, a no ser desviado de la jurisdicción predeterminada ni sometido a procedimientos distintos a los previstos en la ley, a la obtención de una resolución fundada en derecho, a los medios impugnatorios, a que no se revivan procesos fenecidos, a la observancia del principio de legalidad procesal penal, etcétera. La acción será improcedente cuando el agraviado deje consentir la resolución judicial que dice afectarlo. La referencia a la tutela procesal efectiva sustituye a la expresión "proceso regular», que utilizan la Constitución y la legislación anterior.

Un tema que ha merecido especial atención en el Código es el relativo a las causales de improcedencia de los procesos destinados a la protección de los derechos fundamentales (artículo 5), a fin de corregir muchas de las distorsiones cometidas en la utilización e instrumentación de tales procesos, sobre todo tratándose del amparo. Así, se precisa que serán improcedentes las acciones cuyo petitorio de la demanda no se refiera directamente al contenido constitucionalmente protegido del derecho invocado. Con ello se evita que por esta vía se pretenda discutir asuntos que no son estrictamente de índole constitucional, o que no se desprenden del ámbito de la protección constitucional de un derecho. También será improcedente la 
acción cuando existan otros procesos judiciales específicos igualmente satisfactorios y protectores del derecho vulnerado, que establezcan el carácter residual o excepcional del amparo, ante la inexistencia o carencias de otros procesos comunes. Por esta misma razón, el amparo será improcedente si el afectado recurrió, previamente, a otro proceso judicial para la defensa del derecho invocado.

Igualmente, se precisa que serán improcedentes los procesos promovidos contra resoluciones firmes recaídas en otro proceso constitucional (haciendo impertinente el amparo contra amparo, por ejemplo); asimismo, los procesos cuya demanda se interponga luego de haber cesado la vulneración al derecho o de devenido en irreparable en sede constitucional. También serán improcedentes los procesos interpuestos contra resoluciones del Consejo Nacional de la Magistratura, con respecto a la destitución o ratificación de jueces y fiscales, siempre que dichas resoluciones sean motivadas y hayan sido dictadas con previa audiencia al interesado; o los procesos promovidos contra resoluciones de contenido jurisdiccional del Jurado Nacional de Elecciones, salvo que se haya vulnerado la tutela procesal efectiva.

El artículo 22 del Código contiene novedades importantes respecto a la actuación y ejecución de las sentencias por los jueces. Las sentencias dictadas en procesos constitucionales de hábeas corpus, amparo, hábeas data y cumplimiento se actuarán conforme a sus propios términos por el juez que conoció de la demanda y tienen prevalencia sobre cualquier sentencia de otros procesos judiciales. Se faculta al juez a utilizar medios de apercibimiento para asegurar el cumplimiento de la sentencia por el obligado a realizar prestaciones de dar, hacer o no hacer, tales como la imposición de multas fijas o acumulativas, determinadas discrecionalmente por el juzgador según la capacidad económica del obligado, o a disponer la destitución del responsable.

\subsection{El proceso de hábeas corpus}

\subsubsection{Los derechos protegidos}

La Constitución peruana señala que el hábeas corpus protege la libertad individual y los derechos conexos con esta; creemos que, en rigor, debería referirse a la libertad y seguridad personales, pero este asunto no es motivo del presente trabajo. El artículo 25 del Código sigue el mismo criterio establecido en la ley 23506 , en el sentido que contiene una enumeración extensa y enunciativa (no taxativa) de los principales derechos protegidos por medio de este proceso constitucional. Así, se menciona su procedencia frente a detenciones arbitrarias, es decir, cuando estas se realizan sin que medie mandato judicial escrito 
y motivado o flagrante delito; cuando el detenido es arbitrariamente incomunicado o privado del derecho a ser asistido por un abogado defensor desde el momento de la citación o detención policial; cuando se impide el libre tránsito o una persona es expatriada o separada del lugar de su residencia, sin que medie mandato judicial, o es objeto de vigilancia domiciliaria o seguimiento policial injustificados, etcétera.

Pero el Código introduce como novedad la mención expresa (o mejor formulación) de la protección del hábeas corpus respecto a algunos otros derechos, tales como la integridad personal y el derecho a no ser sometido a torturas o tratos inhumanos; a no ser forzado a prestar juramento o declarar reconociendo la propia culpabilidad (autoinculpación o autoincriminación) o la del cónyuge y parientes; a decidir voluntariamente sobre la prestación del servicio militar; a no ser objeto de desaparición forzada; a no ser privado del documento nacional de identidad y a obtener o renovar el pasaporte; el derecho del detenido o recluso de recibir un trato razonable y proporcionado respecto a las condiciones en que cumple el mandato de detención.

Adicionalmente, se aprecia como cambio importante que el derecho a la inviolabilidad del domicilio pasa a ser protegido por el hábeas corpus y ya no por el amparo, mientras que los derechos a la libertad de conciencia y a guardar reserva sobre sus convicciones o creencias de cualquier índole, reciben ahora tutela del amparo y ya no del hábeas corpus.

\subsubsection{Las modalidades de hábeas corpus}

El hábeas corpus "preventivo" está contemplado en el artículo 2 del Código, y precisa que la amenaza de violación del derecho debe ser cierta y de inminente realización. El tradicional hábeas corpus "reparador", que procede frente a las detenciones arbitrarias y persigue la obtención de la libertad, se halla previsto en el artículo 25, inciso 7 del Código. También se contempla el hábeas corpus "restringido" (artículo 25, inciso 13), destinado a poner fin a afectaciones de la libertad personal que, sin llegar a ser una detención, suponen molestias y perturbaciones a esta, como el seguimiento policial o la vigilancia domiciliaria injustificadas.

El hábeas corpus "correctivo" se regula en el artículo 25 , inciso 17 , y es procedente para el cambio de las condiciones a las que se encuentra sometido un recluso o una persona válidamente detenida, cuando estas carecen de razonabilidad o proporcionalidad y suponen una afectación indebida a la dignidad, calidad humana, salud, integridad o seguridad personal de quien se encuentra privado de la libertad. El denominado hábeas corpus "traslativo" se recoge en el artículo 25 , inciso 14 , que lo hace procedente 
para ejecutar la excarcelación dispuesta por el juez para el procesado que cumple detención prolongada o el recluso que permanece en prisión a pesar de haber cumplido su condena. Finalmente, el hábeas corpus "instructivo", contemplado en el artículo 25, inciso 16, regula el procedimiento que se debe seguir en caso de detenciones que suponen una desaparición forzada.

\subsubsection{Algunos aspectos procesales}

El Código reitera que la legitimación para interponer la demanda de hábeas corpus corresponde al agraviado o a cualquier persona en su nombre, sin necesidad de contar con poder o representación; tampoco se requiere firma de abogado ni mayores formalidades. También la puede interponer el Defensor del Pueblo. La demanda se puede presentar por escrito, verbalmente, mediante fax, correo o cualquier medio electrónico de comunicación. Es competente para conocer de este proceso cualquier juez penal, sin importar el turno. No caben recusaciones, salvo por parte del agraviado, y los funcionarios judiciales no pueden excusarse; las actuaciones judiciales son improrrogables, y los jueces deben habilitar día y hora para estas; en este procedimiento no interviene el Ministerio Público.

Cuando el hábeas corpus se refiere a detenciones arbitrarias o agresiones a la integridad personal, el juez debe constituirse inmediatamente al lugar donde se produce la afectación del derecho y resolver en dicho acto, y se debe cumplir su resolución sin esperar a la notificación. En los otros casos, el juez decidirá si se constituye en el lugar o cita al agresor para que explique su conducta, y debe dictar resolución en el término de un día natural. Tratándose de detenciones que supongan una desaparición forzada, si el juez no recibe de las autoridades o funcionarios emplazados información satisfactoria sobre el paradero o destino del agraviado, deberá adoptar todas las medidas que contribuyan a su hallazgo, y dará aviso al Ministerio Público para que realice las investigaciones. Incluso, puede comisionar a otros jueces del distrito judicial donde se estima pueda encontrase el desaparecido. Si la demanda se interpuso contra un miembro de la Policía o de la Fuerza Armada, el juez solicitará a la autoridad superior que informe dentro de las veinticuatro horas.

\subsection{El proceso de amparo}

\subsubsection{El carácter excepcional del amparo}

La ley 23506 de hábeas corpus y amparo estableció, en el artículo 6, numeral 3, la improcedencia de estas acciones "cuando el agraviado opta por 
recurrir a la vía judicial ordinaria». Con ello, se dejaba a criterio y libre elección del agraviado interponer el amparo u otro proceso judicial para la defensa de su derecho constitucional afectado. La expresión "vía judicial ordinaria" ha sido entendida como referida tanto al antiguo "juicio ordinario" (hoy denominado Proceso de Conocimiento en el Código Procesal Civil) como a cualquier otro proceso judicial especial disponible y destinado a lo protectivo del derecho.

La intención de los autores del proyecto que dio lugar a dicha ley, era facilitar la procedencia del amparo y del hábeas corpus, evitando que estas acciones fueran declaradas improcedentes por el órgano judicial, como sucedió muchas veces en el pasado, arguyendo (sin verdadero fundamento jurídico o por sometimiento al poder político de turno) que existían uotras vías" judiciales disponibles. Si bien la intención era loable y se basaba en la experiencia, su aplicación trajo inconvenientes y nuevos problemas. Por un lado, porque cada proceso tiene una naturaleza y una racionalidad propia, que lo hace idóneo o no para la tutela de un derecho, aspecto que no puede quedar librado a la mera voluntad o elección del accionante. Por otro lado, porque la norma facilitó la indebida utilización del amparo por muchos litigantes, aprovechando su carácter de proceso de tutela de urgencia, para la discusión de asuntos que, en estricto, no suponían la protección del contenido constitucionalmente protegido de un derecho o, incluso, ni siquiera de un derecho directamente reconocido por la Constitución.

Es por ello positivo que el Código Procesal Constitucional, en el artículo 5 , numeral 2, establezca que el amparo será improcedente cuando «[...] existan vías procedimentales específicas, igualmente satisfactorias, para la protección del derecho constitucional amenazado o vulnerado». En consecuencia, el amparo adquiere un carácter excepcional o residual, atendiendo a su naturaleza de proceso constitucional y no ordinario, destinado a la protección de un derecho constitucional, cuando se afecta el contenido constitucionalmente protegido de este y no aspectos secundarios o de índole legal, asuntos que deben ventilarse por las vías judiciales comunes. Así, el amparo será procedente para la tutela de urgencia de un derecho constitucional a falta de otras vías judiciales específicas igualmente protectivas y satisfactorias. Es claro que para declarar esta improcedencia del amparo no basta con que existan otros procesos judiciales disponibles, lo que siempre es factible, sino que estos resulten suficientemente satisfactorios para tutelar la pretensión.

Con esta decisión del Código no se desprotege el derecho constitucional sino que se encamina su defensa hacia la vía procesal que, por las características y el objeto de la pretensión, permitan la adecuada tutela del derecho. Asimismo, se pone coto a una de las más severas distorsiones producidas mediante la instrumentación del amparo, ocasionada por la actuación poco 
rigurosa de muchos abogados y litigantes que, lamentablemente, no supo ser corregida por el órgano judicial. Es importante tener presente que en el proceso de amparo no existe propiamente una etapa probatoria, por lo que se podrá desestimar acciones cuya resolución requiera la ejecución de pruebas, causas sujetas a complejo análisis técnico o de probanza, y las que demandan un mayor debate judicial que es impropio de un proceso de urgencia como el amparo. Sin perjuicio de ello, el Código mantiene, en su artículo 5, numeral 3, como causal de improcedencia del amparo que el agraviado haya recurrido previamente a otro proceso judicial para reclamar tutela del derecho constitucional.

\subsubsection{Los derechos protegidos por el amparo}

Como se sabe, el proceso de amparo protege una amplia cantidad de derechos constitucionales, es decir, todos aquellos que no tienen tutela por medio del hábeas corpus y el hábeas data. De allí que el Código, en su artículo 37, siga el criterio razonable anteriormente adoptado en la ley 23506, consistente en enumerar específicamente buena parte de los derechos protegidos y consignar al final del precepto un inciso (en este caso el 25) que incluye a "los demás derechos que la Constitución reconoce». Se observan, no obstante, dos innovaciones importantes en esta materia: por un lado, la mención específica de algunos otros derechos; por otro, la referencia a derechos no protegidos por el amparo.

En el primer caso, sin perjuicio de la reiteración en el listado enumerado de derechos como el de no ser discriminado por causa alguna, la libertad de expresión e información, el ejercicio público de cualquier confesión religiosa; las libertades de contratación, de asociación, de creación artística, de reunión, de trabajo, de sindicación, de participación política, de petición; la propiedad y herencia, la nacionalidad, el derecho a la educación, etcétera; el Código menciona ahora expresamente los derechos a la igualdad, al honor, reputación, intimidad personal, propia voz e imagen, rectificación frente a informaciones inexactas o agraviantes, tutela procesal efectiva (antes denominado a la jurisdicción y proceso), seguridad social, a la remuneración y pensión.

En el segundo caso, el Código dispone en el artículo 38 que «no procede el amparo en defensa de un derecho que carece de sustento constitucional directo o que no está referido a los aspectos constitucionalmente protegidos del mismo". Esta norma se complementa con lo dispuesto en el artículo 5, numeral 2, que torna improcedente el amparo cuando "[...] los hechos y el petitorio de la demanda no están referidos en forma directa al contenido constitucionalmente protegido del derecho invocado". Se trata, 
pues, de circunscribir al amparo a su condición de proceso constitucional, estrictamente referido a la protección de derechos constitucionales; y de proceso excepcional, de turela de urgencia, distinto a los procesos judiciales ordinarios o especiales de otra índole.

El fundamento de esta norma es corregir una grave distorsión observada en la utilización e instrumentación indebida del amparo. A menudo, los litigantes hacen referencia en su demanda a un derecho recogido en la Constitución, pero solo para sustentar una pretensión que, estrictamente, no tenía carácter constitucional o que tampoco formaba parte del contenido esencial del derecho protegido constitucionalmente, sino a aspectos de regulación legal o de naturaleza secundaria, que no deben tutelarse por medio del amparo. Así, por ejemplo, es evidente que el derecho de propiedad incluye la protección de la posesión, pero la posesión — por sí misma - no es un derecho constitucional, por lo que el mero poseedor que no es propietario no puede invocar la defensa de este derecho en un amparo. A su vez, la Constitución protege con el amparo derechos como la libertad de contratación o la de asociación; pero ello, no autoriza a que cualquier discrepancia o desavenencia suscitada en la ejecución de un contrato o en la marcha de la entidad asociativa se pretenda dilucidar o resolver por el amparo, salvo aquellos aspectos directamente ligados al contenido esencial constitucionalmente protegidos del derecho.

\subsubsection{Medida cautelar y suspensión del acto reclamado}

El artículo 15 del Código se ocupa de las medidas cautelares y de la suspensión del acto reclamado, que son aplicables a los procesos de amparo, hábeas data y cumplimiento; estas proceden cuando resulten necesarias para asegurar la eficacia ulterior de la pretensión y de la sentencia, siempre que exista apariencia del derecho reclamado y peligro de perjuicio por la demora del proceso. El juez, al momento de concederla, tendrá que poner atención en la posible irreversibilidad de la medida cautelar.

La medida se dictará y ejecutará sin escuchar a la parte demandada; la apelación no tiene efecto suspensivo, por lo que la medida cautelar se ejecuta a pesar de interpuesta la impugnación. Con ello se eliminan las notorias restricciones vigentes a las medidas cautelares en el amparo, que las tornaban engorrosas $y$, muchas veces, ineficaces. $\mathrm{Y}$ es que la legislación anterior exigía correr traslado del pedido de medida cautelar tanto al demandado como al fiscal civil disponiendo que, si se concedía la medida, su apelación tenía efectos suspensivos, lo que impedía su ejecución hasta la decisión definitiva de segundo grado. 
Sin embargo, el Congreso introdujo una injustificada modificación en el proyecto original del Código, respecto a las medidas cautelares en amparos dirigidos contra actos administrativos provenientes de municipalidades y gobiernos regionales, otorgándoles un procedimiento especial francamente cuestionable. Su tramitación no corresponderá a los jueces sino a la Sala de la Corte Superior; del pedido se correrá traslado al demandado, y se abrirá un incidente (por cuerda separada) con participación del Ministerio Público y previendo incluso el informe oral. La resolución será apelable ante la Corte Suprema con efecto suspensivo, lo que determina que no se ejecute la medida concedida hasta la decisión final. Con ello, en estos casos, se reiteran todas las deficiencias y críticas aplicables actualmente a la medida cautelar en el amparo. Asimismo, se establece una inaceptable (e inconstitucional) distinción en función de la naturaleza particular del emplazado, lo que vulnera la igualdad dentro del proceso.

Respecto a la vigencia y extinción de la medida cautelar decretada, el artículo 16 del Código dispone que esta solo se extingue cuando la resolución que pone término al proceso adquiere la autoridad de cosa juzgada; de modo que no será revocada en el supuesto que una sentencia de primer grado desestime la demanda. Si la sentencia final es estimatoria del amparo, la medida cautelar se convierte en medida ejecutiva y conservan sus efectos hasta la plena satisfacción del derecho o hasta que el juez expida una resolución modificatoria o extintiva en la fase de ejecución. En cambio, si la sentencia final desestima la demanda, se procederá a la liquidación de costas y costos del proceso cautelar, y quien sufrió la medida puede solicitar responsabilidad y el juez concederle adicionalmente el pago de daños. El juzgador también podrá imponer una multa a quien solicitó la medida cautelar.

\subsubsection{Algunos aspectos procesales}

El titular del derecho afectado es el legitimado para interponer el amparo (artículo 39). Puede también hacerlo su representante procesal, con el sustento de poder que no tiene que estar inscrito en los Registros Públicos. Tratándose de la defensa del ambiente y de otros derechos difusos reconocidos por la Constitución, la acción puede ser promovida por cualquier persona o por instituciones sin fines de lucro dedicadas a este objeto. El Defensor del Pueblo también se encuentra legitimado para interponer el amparo en el ámbito de sus competencias (artículo 40). El artículo 41 contempla la procuración oficiosa, y habilita a cualquiera a interponer el amparo en favor de alguien de quien no tiene representación, siempre que este se encuentre imposibilitado de hacerlo directamente y que ratifique la demanda y la actividad procesal realizada cuando se halle en posibilidad de hacerlo. 
El plazo de prescripción (denominado de caducidad por la anterior ley) para la interposición de la demanda de amparo es de sesenta días hábiles, contados desde que se produjo la afectación del derecho, siempre que el agraviado haya tenido conocimiento del acto lesivo y estado en posibilidad de interponerla. Tratándose de amparo contra resoluciones judiciales, el plazo de prescripción se computa desde que la resolución quedó firme, y debe interponerse la demanda dentro de los treinta días hábiles de notificada la resolución que manda cumplir la decisión. En el artículo 44 se detalla la forma de cómputo del plazo de prescripción en distintos supuestos; destaca la referencia a que, en caso de amenaza, no corre el cómputo de dicho plazo hasta cuando la agresión se produce; si la vulneración se origina en una omisión, el plazo no transcurre mientras esta subsista.

Para que la demanda de amparo sea procedente, se requiere antes el agotamiento de la via previa; en tal supuesto, el plazo de prescripción solo empezará a correr luego de cumplido este requisito. El artículo 46 del Código contempla las excepciones a la obligación de agotar la vía previa, siendo estas: a) cuando una resolución, que no sea la última en la vía administrativa, se ejecute sin esperar a que se venza el plazo para que quede consentida; b) cuando por el agotamiento de la vía previa la agresión podría convertirse en irreparable; c) cuando la vía previa no se encuentra regulada o ha sido innecesariamente iniciada por el afacetado; d) cuando la vía previa no es resuelta dentro del plazo previsto para su resolución.

El juez podrá rechazar liminarmente la demanda, en caso de que esta sea manifiestamente improcedente, por encontrarse en algunas de las causas sindicadas en el artículo 5 del Código. Si el amparo persigue el derecho de rectificación, también cabe el rechazo liminar si no se acredita haber dirigido una comunicación previa al director del medio de comunicación para que realice esta. Si la resolución de rechazo liminar por improcedencia es apelada, el juez pondrá al demandado en conocimiento del recurso. En el proceso de amparo no cabe reconvención ni abandono, pero si desistimiento. Procede la acumulación subjetiva de oficio, cuando de la demanda o contestación el juez observa la necesidad de incorporar a la relación procesal a terceros no emplazados, si la decisión a recaer en el proceso podría afectarlos. También cabe la acumulación de procesos de amparo, de oficio o a pedido de parte, en el juez que primero previno.

El amparo se interpone ante el juez civil; si se promueve contra una resolución judicial, se hace ante la Sala Civil de la Corte Superior respectiva. De la demanda se correrá traslado por cinco días; si se interponen excepciones, defensas previas o pedidos de nulidad del auto admisorio, se correrá traslado por dos días al demandante. El juez podrá realizar las actuaciones que estime necesarias, sin necesidad de notificación; podrá citar a una audiencia única a 
las partes y sus abogados para los esclarecimientos del caso. Dictará sentencia en la misma audiencia o en un plazo que no excederá de cinco días de culminada esta. La sentencia es apelable dentro de los tres días de notificada.

El trámite de la apelación supondrá conceder tres días al apelante para que exprese agravios, corriendo traslado de estos por un término similar a la otra parte. El Código ha eliminado, creemos que acertadamente, la intervención del Ministerio Público en esta instancia, que contemplaba la legislación anterior, y que resultaba innecesariamente dilatoria. Se citará para la vista de la causa, donde podrá solicitarse el informe oral de los abogados. Se expedirá sentencia dentro de los cinco días posteriores a la vista. Sin perjuicio de las disposiciones generales sobre ejecución de sentencias de hábeas corpus, amparo, hábeas data y cumplimiento, el artículo 59 del Código consigna diversos apremios y requerimientos especiales para el cumplimiento de la sentencia de amparo, lo que puede incluir la apertura de proceso administrativo al funcionario responsable y su superior, así como sanciones por desobediencia.

\subsection{El proceso de hábeas data}

\subsubsection{Los derechos protegidos}

El proceso de hábeas data protege, específica y exclusivamente, el derecho de acceso a la información en poder de instituciones públicas, es decir, a solicitarla y obtenerla sin necesidad de expresión de causa y con el solo pago del costo de la atención del pedido; así como el derecho a la protección y control del registro y la circulación de los datos personales (autodeterminación informativa) en resguardo de la intimidad. Como es frecuente en otros ordenamientos nacionales, el Código extiende al hábeas data las principales reglas procesales propias del amparo, con algunas pocas peculiaridades.

Respecto al acceso a la información que obre en poder de cualquier entidad pública o estatal, el artículo 61, numeral 1 , del Código precisa que ello incluye a la información que estas instituciones generen, produzcan, procesen o posean, y a la contenida en expedientes terminados o en trámite, estudios, opiniones, dictámenes, informes técnicos, datos estadísticos o cualquier otro documento. También se indica que no importa la forma de expresión en que se encuentre contenida dicha información, y esta puede ser gráfica, sonora, visual, electromagnética o de cualquier otro soporte material.

Creemos importante precisar que esta información existente en entidades públicas debe tener un "contenido público", es decir, que no esté referida a aquellos aspectos excluidos por el propio artículo 2, numeral 5 de la Constitución, o sea, vinculada a la intimidad personal, seguridad nacional 
o materias expresamente excluidas de acceso público por la ley. Este derecho constitucional, cuyo ejercicio es protegido procesalmente y estimulado por el Código, permite contribuir a la mayor transparencia y al acceso público de la información, así como a la ruptura de la "cultura del secreto", tradicionalmente aplicada por la Administración Pública. Ello constituye un indudable avance para la democratización y el control ciudadano de la gestión de las entidades estatales.

En el caso del derecho a la autodeterminación informativa, su configuración autónoma es un fenómeno más bien reciente, como resultado y efecto del vertiginoso desarrollo de la informática y de las nuevas tecnologías de la comunicación. Involucra la protección y el control del titular del derecho frente al registro, utilización y transmisión informática de sus datos personales, sean los de carácter íntimo o "sensibles", como los que - a pesar de no tener estrictamente dicho carácter- igualmente merecen ser objeto de control y reserva.

El derecho a la autodeterminación informativa y la protección frente al uso informático de los datos personales fue incorporado a nuestro ordenamiento constitucional recién con la Carta de 1993, aunque sin una denominación específica y con notorias insuficiencias y limitaciones. Ello no solo desdibuja y restringe severamente sus alcances, sino que afecta sus posibilidades de aplicación y eficacia. Y es que el derecho a la autodeterminación informativa supone brindar protección frente a posibles riesgos o abusos derivados del registro y utilización informática de los datos personales, proporcionando al titular afectado las facultades siguientes: acceder o conocer las informaciones y datos relacionados con su persona, existentes en archivos, registros o bancos de datos informatizados; actualizar la información o rectificar los datos inexactos; lograr la exclusión o supresión de los "datos sensibles», que no deben ser objeto de registro ni de difusión, a fin de salvaguardar la intimidad personal o de impedir la eventual discriminación; así como poder oponerse a la transmisión y difusión de estos.

Es de lamentar que el inciso 6 del artículo 2 de la Constitución Peruana de $1993^{3}$ recoja este derecho en forma defectuosa e insuficiente, pues solo autoriza expresamente al titular a oponerse a que se suministren informaciones que afecten su intimidad personal y familiar. Una interpretación literal de esta norma constitucional, que obviamente descartamos, no incluiría el derecho de la persona a acceder (conocer y recibir) a la información o datos que le conciernen y que se hayan registrados en el banco de

3 Constitución, artículo 2, inciso 6: "Toda persona tiene derecho: [...] A que los servicios informáticos, computarizados o no, públicos o privados, no suministren informaciones que afecten la intimidad personal y familiar». 
datos. Y sin esta facultad, mal pueden ejercitarse acciones como solicitar y exigir la rectificación o actualización de datos inexactos o falsos ni, mucho menos, la supresión de datos sensibles o reservados que afectan la intimidad personal o familiar.

Sin perjuicio de estas deficiencias de la norma constitucional respecto al contenido y alcances del derecho a la autodeterminación informativa, resultó un avance la ley 27490, "Ley que regula las Centrales Privadas de Información de Riesgos y de protección al titular de la informaciónm. En el artículo 13 de dicha norma se consigna como derechos de la persona, cuyos datos se encuentran registrados, el acceso a la información referida a sí misma; el derecho de modificar o cancelar la información que sea ilegal, inexacta, errónea o caduca; así como el derecho a rectificar la información que haya sido suministrada y adolezca de tales vicios. La ley 27863 añadió como derecho del titular la actualización de la información sobre pagos parciales o totales realizados.

En este marco, adquiere mayor relevancia el aporte del Código, pues en su artículo 61, numeral 2, se desarrolla la norma constitucional y se corrigen las insuficiencias anotadas, señalando expresamente como derechos del titular conocer, actualizar, incluir y suprimir o rectificar la información o datos referidos a la persona, que se encuentren almacenados o registrados en forma manual, mecánica o informática, en archivos, bancos de datos o registros, de entidades públicas o privadas que brinden servicio o acceso a terceros. Igualmente, se contempla el derecho a hacer suprimir o impedir que se suministren informaciones o datos de carácter sensible o privado que afecten derechos constitucionales, mención más amplia que no solo protegería la intimidad personal o familiar sino también la eventual afectación del derecho a no ser discriminado por la información personal que se recoge o trasmite por medios informáticos.

\subsubsection{Las entidades que pueden ser emplazadas con el hábeas data}

Otra deficiencia de la norma constitucional comentada está referida a la poco clara determinación de las entidades o instituciones que pueden ser emplazadas, en ejercicio del derecho a la autodeterminación informativa, por el titular de los datos personales mediante el hábeas data. La norma comentada señala que se trata de "servicios informáticos", sean computarizados o no, públicos o privados. Con ello, cabría entender que se refiere a entidades cuya actividad está relacionada con el recojo, archivo, sistematización, transmisión y suministro de datos en forma informática; con la finalidad de brindar servicio informativo, de registro o de consulta destinado al público o a terceros. 
Sin embargo, la utilización de la denominación "servicios informáticos" resulta equívoca pues, de acuerdo a una interpretación literal, sugiere que solo involucraría a instituciones públicas o empresas privadas que proporcionan o venden servicios informativos a terceros. Si ello fuera así, se podría llegar al absurdo que ciertos registros, archivos o bancos de datos personales que poseen organismos estatales (Ministerio del Interior, Dirección de Migraciones, Policía, Municipalidades) o ciertas entidades privadas, podrían quedar excluidos de los alcances de la norma constitucional, alegando que no son un "servicio", en la medida en que la finalidad de sus sistemas informáticos es servir de apoyo a su actividad funcional interna, mas no suministrar informaciones a terceros ni poner dichos datos a disposición o consulta del público en general.

No creemos que esta interpretación restrictiva de la norma constitucional sea la más razonable. Debe entenderse que se puede interponer el hábeas data contra entidades estatales o privadas cuando sus registros, bancos de datos o archivos sobre datos personales brindan servicios e información a terceros o pueden ser consultados por el público.

\subsubsection{Algunos aspectos procesales}

Al proceso de hábeas data le son aplicables las mismas reglas procésales que al amparo (artículo 65). No obstante, una diferencia particular es que se ha eliminado la exigencia de la legislación anterior de agotar la "vía previa", denominación que impropiamente se refería al envío de una carta notarial de requerimiento al emplazado, con 15 días de anticipación, antes de la interposición de la demanda judicial. Ahora, el artículo 62 del Código plantea como requisito que la solicitud conste en documento de fecha cierta, sin que se atribuya a este requerimiento el carácter de "vía" previa.

El plazo para que el emplazado dé respuesta o atienda al pedido es de diez días útiles, si se trata de información solicitada a entidades estatales, y de dos días útiles cuando versa sobre la protección de datos personales. Vencidos dichos plazos y a falta de una acción satisfactoria del requerido, procederá la interposición del hábeas data ante el juez civil. La observancia de estos plazos puede eliminarse en caso de acreditarse que su cumplimiento puede crear el peligro de un daño irreparable. Otra diferencia importante respecto al amparo es que la exigencia de patrocinio de abogado resulta facultativa. Ello es positivo y justificado pues, en muchos casos, el pedido de información no ofrece mayor complejidad jurídica, lo que no amerita el concurso de abogado y facilita la más amplia utilización de este proceso, al reducir el costo de interposición y tramitación del hábeas data. 


\section{El control de constitucionalidad y legalidad de las normas: acción popular y de inconstitucionalidad}

El Código se ocupa en el Título VI de las disposiciones generales aplicables tanto a los procesos de inconstitucionalidad como de acción popular, dado que ambos suponen un control de la regularidad constitucional y legal de las normas de carácter general y del principio de jerarquía en el ordenamiento normativo (artículo 75). Ello sin perjuicio, claro está, de la regulación especial y separada que reciben cada uno de estos procesos constitucionales en los Títulos VII y VIII, respectivamente.

El proceso de acción popular se tramita y resuelve exclusivamente ante el Poder Judicial, mientras que el de inconstitucionalidad se dirige directamente ante el Tribunal Constitucional. Las sentencias firmes de ambos órganos en esta materia adquieren autoridad de cosa juzgada, son vinculantes para todos los poderes públicos y tienen efectos generales desde el día siguiente de la fecha de su publicación (artículo 82). Si la demanda se declara fundada, ello acarreará la derogación de la norma cuestionada. Los jueces suspenderán la tramitación de procesos de acción popular cuando involucren normas cuya inconstitucionalidad se encuentre pendiente de resolución ante el Tribunal Constitucional, hasta que este expida la sentencia respectiva (artículo 80).

\subsection{El proceso de acción popular}

El proceso de acción popular, según precisa el artículo 76 , procede contra los reglamentos, normas administrativas y resoluciones de carácter general, cualquiera sea la autoridad pública de que emanen, siempre que infrinjan la Constitución o la ley, o cuando no hayan sido expedidas o publicadas en la forma que la Constitución o la ley señalan. La demanda puede ser interpuesta por cualquier persona (artículo 84), ante la Sala de la Corte Superior de Lima que corresponda según la materia, cuando se trata de normas de alcance nacional; si la norma tiene carácter regional o local, será competente la Sala de la materia de la Corte Superior del Distrito Judicial donde se ubica el órgano emisor (artículo 85).

El plazo de prescripción para la interposición de la demanda de acción popular es de cinco años, contados a partir del día siguiente de la fecha de publicación de la norma cuestionada (artículo 87). La Sala deberá pronunciarse sobre la admisibilidad de la demanda en un plazo no mayor de cinco días desde su presentación (artículo 88). El auto admisorio se publicará por una vez en el diario oficial, así como una síntesis de la demanda, y se correrá traslado al órgano emisor de la norma, según las especificaciones consigna- 
das en el artículo 89 del Código. Los plazos para la contestación de la demanda, para la realización de la vista de la causa y la expedición de sentencia son, en cada caso, de diez días, respectivamente.

La sentencia podrá ser apelada, dentro de los cinco días de notificada, ante la Sala Constitucional y Social de la Corte Suprema; también se elevará en consulta a esta en caso de no plantearse apelación. La sentencia final se dictará dentro de los diez días posteriores a la vista de la causa, siendo publicada en el diario oficial, lo que hará las veces de la notificación. A diferencia de lo que sucede en el proceso de inconstitucionalidad, el artículo 94 del Código trae como importante novedad la posibilidad de que se decrete una medida cautelar, siempre que la sentencia de primer grado sea estimatoria de la demanda, lo que supondrá la suspensión de la eficacia de la norma cuestionada.

La sentencia del proceso de acción popular que declara fundada la demanda, no solo tiene efectos generales y derogatorios de la norma inconstitucional o ilegal sino que también puede establecer su nulidad con efectos retroactivos. En tal supuesto, la sentencia determinará sus efectos en el tiempo (artículo 81, tercer párrafo). Esta es una diferencia sustancial respecto a las sentencias fundadas en los procesos de inconstitucionalidad, que no tienen efecto retroactivo por disposición expresa del artículo 204, segundo párrafo de la Constitución.

\subsection{El proceso de inconstitucionalidad}

Siguiendo lo establecido por el artículo 200, numeral 4, de la Constitución, el artículo 77 del Código dispone que el proceso de inconstitucionalidad procede contra las normas de rango legal, es decir, leyes, decretos legislativos, decretos de urgencia, tratados internacionales, reglamentos del Congreso, normas regionales de carácter general y ordenanzas municipales; que contravengan la Constitución por razones de fondo o de forma. El artículo 75 , en su segundo párrafo, agrega que puede demandarse la inconstitucionalidad de las leyes, decretos legislativos o de urgencia que hayan regulado o modificado materias reservadas a leyes orgánicas, sin haberse aprobado con los requisitos y formalidades propias de estas.

Siguiendo el artículo 203 de la Constitución, el Código dispone que están legitimados para interponer el proceso de inconstitucionalidad el Presidente de la República, el veinticinco por ciento del número legal de congresistas, el Fiscal de la Nación, el Defensor del Pueblo, los presidentes de los gobiernos regionales, con acuerdo de su consejo, y los alcaldes de los gobiernos locales, con acuerdo del concejo municipal; en estos dos últimos casos, solo en asuntos de su competencia. También están facultados para 
demandar la inconstitucionalidad cinco mil ciudadanos con firmas comprobadas, salvo cuando se cuestiona una ordenanza municipal, caso en que se requerirá el $1 \%$ de los ciudadanos del respectivo ámbito territorial, siempre que este porcentaje no exceda la cifra antes señalada. Asimismo están legitimados los colegios profesionales, en materias de su especialidad. En el artículo 99 del Código se detalla la forma en que cada una de las instituciones y personas legitimadas pueden interponer la demanda, para efectos de su representación procesal.

En el artículo 100 se señala que el plazo para interponer la demanda de inconstitucionalidad es de seis años, contados desde la fecha de su publicación; en el caso de los tratados, en cambio, el plazo es de solo seis meses. Los artículos 101 y 102 precisan los requisitos mínimos que debe contener la demanda y los anexos que deben acompañarla, manteniendo en lo esencial lo regulado actualmente por la Ley Orgánica del Tribunal Constitucional 26435; la novedad es la exigencia de acompañar una copia de la norma objeto de la demanda, e indicar la fecha exacta de su publicación.

Interpuesta la demanda, el Tribunal Constitucional deberá pronunciarse sobre su admisión en un plazo que no puede exceder de diez días (artículo 103). El Código introduce una interesante diferencia entre las causales de inadmisibilidad de la demanda y las de su improcedencia. Así, la demanda será declarada inadmisible (artículo 103) si carece de alguno de los requisitos de contenido o anexos antes señalados; si se tratara de una omisión subsanable, se otorgará al demandante un plazo no mayor de cinco días para hacerlo. En cambio, según el artículo 104, el TC podrá declarar liminarmente la improcedencia de la demanda en caso que esta haya sido interpuesta vencido el plazo de prescripción, cuando el Tribunal haya desestimado anteriormente una demanda de inconstitucionalidad por razones de fondo sustancialmente iguales a la pretensión, o si carece de competencia para pronunciarse sobre la norma impugnada.

El Código, en el artículo 105, dispone la improcedencia de medidas cautelares tratándose de un proceso de inconstitucionalidad. Atendiendo al interés público del proceso, el TC deberá impulsar de oficio su desarrollo, prescindiendo de la actividad o interés de las partes. El proceso solo termina por sentencia (artículo 106). Corrido traslado de la demanda, el Código establece que el plazo para contestarla será de treinta días (artículo 107), y de diez días útiles ulteriores a esta para la vista de la causa. Los abogados de las partes podrán realizar informe oral en la vista de la causa; la sentencia deberá dictarse dentro de los treinta días posteriores a la producción de dicha vista (artículo 108). 
Conforme señala la Constitución, el artículo 81 del Código establece que la sentencia que declara la inconstitucionalidad de una norma de rango legal tiene alcance general y carácter derogatorio, pero no efecto retroactivo ni puede reabrir procesos judiciales concluidos donde se haya hecho aplicación de la norma declarada inconstitucional. Las únicas excepciones a la regla de irretroactividad de los efectos de la sentencia de inconstitucionalidad son la materia penal, para la aplicación de la retroactividad benigna, y cuando la sentencia se pronuncie sobre normas de materia tributaria, que se hayan dictado violando el artículo 74 de la Constitución. En este último supuesto, el Tribunal deberá señalar expresamente los efectos en el tiempo de su decisión, lo que abriría la posibilidad de que tales sentencias puedan tener efecto retroactivo. En todo caso, siempre en materia tributaria, el Tribunal deberá resolver en la sentencia lo pertinente a las situaciones jurídicas que se verificaron mientras la norma declarada inconstitucional estuvo en vigencia. Por la declaración de inconstitucionalidad de una norma legal no recobran vigencia las disposiciones legales que esta hubiera derogado (artículo 83).

\section{Reflexión final}

Ciertamente este Código Procesal Constitucional introduce avances importantes con la intención de contribuir a la mejor protección de los derechos fundamentales y a la preservación de la constitucionalidad. El hecho de que la norma tenga como marco lo dispuesto por la vigente Constitución solo ha impuesto algunas limitaciones, en especial con respecto al acceso restringido ante el Tribunal Constitucional en los procesos de hábeas corpus, amparo, hábeas data y cumplimiento; o a la no participación del TC como última instancia en los casos en los que se aplica el control difuso de constitucionalidad. Lo que sí es cuestionable es la incorporación por el Congreso de un trato diferenciado para la tramitación y efectos de las medidas cautelares, en los procesos de amparo, cuando el demandado es un gobierno municipal o regional. Creemos que se trata de una decisión inconveniente, a la par de inconstitucional.

Pero, en definitiva, el Código apuesta a fortalecer el rol de la judicatura en el manejo y resolución de estos procesos constitucionales. Dependerá pues de su capacidad jurídica, y de su compromiso real con los valores y derechos constitucionales, si los nobles propósitos de este Código Procesal Constitucional peruano se ven realizados. 